\title{
Driving and Deterrent Factors Affecting Organic Food Consumption in Vietnam
}

\author{
Loan H. Tran, Barbara Freytag-Leyer, Angelika Ploeger, and Thomas Krikser
}

\begin{abstract}
This study aims to determine driving factors significantly influencing the purchase intention and to identify impediments creating the intention -behavior gap regarding organic food consumption in Vietnam. The chosen driving factors affecting the organic food purchase intention in this study are health benefits, environmental awareness, and social norms, whereas trust, price, and convenience as well as availability are investigated as deterrent factors of the link between intention and behavior. A structured online questionnaire with snow-balling sampling method was distributed to collect a representative sample of 466 Vietnamese consumers nationwide. A five-point likert scale was used for the level of approval for 36 statements. Statistical tools of SPSS 22.0 including descriptive analysis, principal component analysis, and multiple regression analysis models were used for data analysis. The results showed that health benefits, environmental awareness, and social norms were facilitators of organic food purchase intention. Although high intention to purchase organic foods was identified in Vietnam, it was not translated into actual purchase behavior. The main barriers for the inconsistency were premium price and low availability of organic products or inconvenience to buy in the market. Lack of trust insignificantly impacted on organic food choices among Vietnamese consumers in this study. These empirical findings and suggestions are beneficial for all players across supply chains.
\end{abstract}

Index Terms-Consumer behavior, intention-behavior gap, organic food purchase intention, Vietnam.

\section{INTRODUCTION}

Organic food consumption is a movement to shift towards sustainable development and contributes to achieving the sustainable development goals [1]. Organic food is produced in accordance to organic production standards, aimed at harmonizing the economically, socially and environmentally sustainable development. Organic agriculture and further supply chains such as organic food processors, wholesalers, and retailers have to comply with organic standards to ensure the integrity of the products [2].

Vietnam is located in Southeast Asia with its population of over 96 million. The country escaped from one of the poorest

Manuscript received November 9, 2018; revised February 11, 2019. Financial support and online survey platform were sponsored by University of Kassel, Germany.

Loan H. Tran was with Faculty of Organic Agricultural Sciences, University of Kassel and Department of Nutritional, Food and Consumer Studies, Fulda University of Applied Sciences, Germany (e-mail: hongloan2368@gmail.com).

Barbara Freytag-Leyer is with Department of Nutritional, Food and Consumer Studies, Fulda University of Applied Sciences, Germany (e-mail: barbara.freytag-leyer@oe.hs-fulda.de).

Angelika Ploeger and Thomas Krikser are with Faculty of Organic Agricultural Sciences, University of Kassel, Germany (e-mail: a.ploeger@uni-kassel.de, t.krikser@uni-kassel.de). countries in the world and has reached to the level of the lower-middle income country since 2009 [3]. However, the rapidly economic growth has traded off deforestation, water pollution, land degradation, and biodiversity loss [4], [5]. Indeed, to boost up high yields of agricultural products, the expansion of agricultural land and intensive farming with the heavy use of synthetic fertilisers, pesticides, and other agrochemicals are conducted [6]. Organic agriculture and its products are emerging as the alternative choices for Vietnamese farmers and consumers to switch to sustainable production and consumption [7]. The domestic market share of organic vegetables is still negligible due to insufficient information on organic products for consumers, inconvenience to buy, or mistrust of the food safety. Further, a niche market of organic foods is mainly concentrated in metropolitan areas [8].

A large number of empirical studies and literature reviews on organic food consumption have been conducted for the western world since years, and the amount of the research for Asian regions has been on the rise [9]. As compared with neighboring countries such as Indonesia, Malaysia, and Thailand, a few studies have explored Vietnamese consumer behavior towards organic foods, and mainly focused on two biggest cities namely Hanoi and Ho Chi Minh City. Moreover, there has been little research on the inconsistencies between the intention and the behavior towards organic foods [10] Therefore, the aim of this study is to determine the motives for the purchase intention of organic foods and to identify barriers creating the intention - behavior gap relevant to organic food purchase decision in Vietnam.

\section{THEORETICAL BACKGROUND AND CONCEPTUAL FRAMEWORK OF THE STUDY}

Organic food consumption is considered as one of the sustainable diets because it meets the high expectation of health, nutrition aspects and environmental friendliness among modern consumers [11]. The driving factors for organic food choices commonly investigated are health benefits, environmental concerns, product attributes, social norms, ethics, whereas lack of trust, high price, short expiry dates and low availability are emerged as the major barriers towards organic product purchase [12]-[14]. These impediments are usually found in developing countries rather than developed economies [11], [15].

The inconsistency between intention and consumer behavior has been found in earlier studies [16]. Olander and Thøgersen suggested the motivation, opportunity, and ability (MOA) model to identify the gap between intention and actual behavior [17]. The intention, capturing motivational factor, is 
the function of attitude towards the behavior and social norms [18]. Opportunity and ability are considered as the two determinants bridging the gap between intention and action (behavior) of consumers. Opportunity, comprising of price and convenience \& availability to buy organic products, refers to the overall, contextual and situational conditions that moderate the behavior. Ability, including trust and knowledge, is conceived as the subjective precondition for the behavior [17]. It is of great difficulty to identify all influencing factors on the actual purchasing behavior [18]. Hence, this study chose some factors to determine the motives for the intention and barriers for the actual behavior as depicted in Fig. 1.
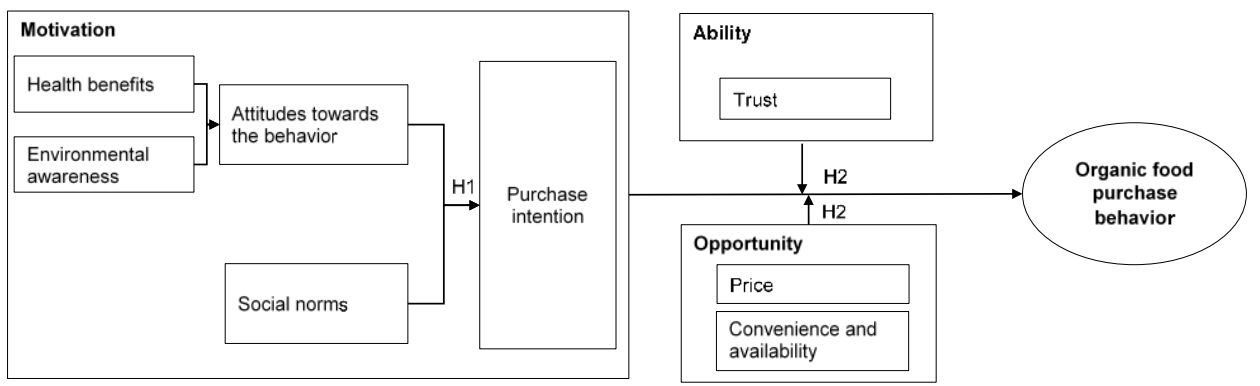

Fig. 1. Research framework of the study.

\section{RESEARCH METHODOLOGY}

\section{A. Research Hypotheses}

The main precursors leading to positive consumer attitudes are embedded attributes of organic products such as health, taste, quality, food safety, environmental friendliness and animal welfare [19], [20]. Among these attributes, health consciousness and environmental concern, antecedents of attitudes, are generally perceived as the important features of organic food across different cultures [21], [22]. Social norms are perceived as the impact of referents (e.g. friends, family, doctors, sales staffs, etc.) on the individuals' intention to perform the behavior [18]. Therefore, the first hypothesis is proposed as follows:

Hypothesis 1 (H1): Attitudes (health benefits and environmental awareness) towards the behavior and social norms significantly influence the organic food purchase intention.

Ajzen admitted that various components can contribute to the failure of acting on consumers' intentions. It is termed as the intention-behavior gap [18]. Recent psychological studies indicated that the discrepancy between intention and behavior to purchase organic food can be led by several deterrent factors such as high price, inconvenience or unavailability of organic products, and distrust in organic certificates, producers, stores, etc. [14], [19], [21]. From then, the second hypothesis is put forward:

Hypothesis 2 (H2): Trust, convenience and availability, and price negatively influence the organic food purchase behavior.

\section{B. Data Collection and Analysis}

A web-based survey was carried out to collect the primary data. The findings of previous literatures together with experts' suggestion were the background of the questionnaire development. The questionnaire was originally designed in English, and then translated into Vietnamese. 36 statements were presented to cover different themes of health benefits, environment awareness, social norms, price, convenience \& availability, trust and the intention to buy organic foods (see appendix - Table I). The level of agreement of each statement was measured on the five-point likert scale, ranging from " 1 Strongly disagree" to " 5 - Strongly agree". The estimation of the current actual behavior of purchasing organic foods was the share of organic food expenditure over total food expenses. A pilot test was conducted to find out the reliability, validity, time taken for completion and the ease of understanding of the questionnaire. The official data collection took place in September and October 2017 with snow-balling sampling method. Facebook and emails were the supporting tools for spreading out the survey link to Vietnamese people in Vietnam. Ultimately, 466 valid questionnaires were obtained for data analysis. Details of demographic profile of respondents are illustrated in appendix - Table II. IBM SPSS statistics 22.0 was the main statistical tool that was used to analyze the data in this study. Descriptive analysis, principal component analysis, and multiple regression analysis models were computed to describe the data overview, and to explore relationships within the dataset.

TABLE I: VARIABLES FOR ALL STATEMENTS IN THE QUESTIONNAIRE

\begin{tabular}{|c|l|}
\hline $\begin{array}{c}\text { Variable } \\
\text { name }\end{array}$ & \multicolumn{1}{c|}{ Statements } \\
\hline Health_1 & Organic foods are safer to eat than conventional foods \\
\hline Health_2 & $\begin{array}{l}\text { Organic foods have more nutrition than conventional ones } \\
\text { (Ex: higher vitamin content) }\end{array}$ \\
\hline Health_3 & $\begin{array}{l}\text { Consuming organic foods is better for health than } \\
\text { conventional foods. }\end{array}$ \\
\hline Health_4 & $\begin{array}{l}\text { Consuming organic foods reduces the risk of illness in my } \\
\text { family }\end{array}$ \\
\hline Health_5 & $\begin{array}{l}\text { Consuming organic foods avoids health risks that may be } \\
\text { associated with eating non-organic foods }\end{array}$ \\
\hline Envi_1 & Organic foods contribute to reduce the pollution of the soil. \\
\hline Envi_2 & Organic foods contribute to preserve biodiversity. \\
\hline Envi_3 & Organic foods contribute to reduce the amount of waste. \\
\hline Envi_4 & $\begin{array}{l}\text { Organic foods contribute to reduce the ozone hole in the } \\
\text { atmosphere. }\end{array}$ \\
\hline Envi_5 & $\begin{array}{l}\text { Organic foods contribute to reduce the use of petrol and } \\
\text { other nonrenewable sources of energy. }\end{array}$ \\
\hline SN_1 & My family and friends recommend me to buy organic foods. \\
\hline SN_2 & Consuming organic foods is fashionable. \\
\hline SN_3 & $\begin{array}{l}\text { Doctors or well-known people think that organic food is a } \\
\text { good choice. }\end{array}$ \\
\hline SN_4 & Sales staffs in the food stores advise me about organic foods. \\
\hline Price_1 & $\begin{array}{l}\text { There is no special feature of organic foods that can justify a } \\
\text { higher price. }\end{array}$ \\
\hline Price_2 & Higher price of organic food prevents me from buying it. \\
\hline
\end{tabular}




\begin{tabular}{|c|l|}
\hline $\begin{array}{c}\text { Variable } \\
\text { name }\end{array}$ & \multicolumn{1}{|c|}{ Statements } \\
\hline Price_3 & $\begin{array}{l}\text { The price is not fair in comparison to the quality of the } \\
\text { organic food products. }\end{array}$ \\
\hline Price_4 & $\begin{array}{l}\text { I do not want to pay the high price for short shelf-life organic } \\
\text { food products. }\end{array}$ \\
\hline Conv_1 & $\begin{array}{l}\text { There are few grocery stores selling organic foods close to } \\
\text { where I live or work. }\end{array}$ \\
\hline Conv_2 & $\begin{array}{l}\text { I have to order the organic food I would like to buy some } \\
\text { days before I get it. }\end{array}$ \\
\hline Conv_3 & Organic foods have a limited range of choices. \\
\hline Conv_4 & $\begin{array}{l}\text { The stores that I frequently shop do not sell a variety of } \\
\text { organic foods. }\end{array}$ \\
\hline Conv_5 & Organic food is only available in limited stores / markets. \\
\hline Trust_1 & $\begin{array}{l}\text { I trust the institutions (e.g. independent organizations, } \\
\text { non-profit organizations) certifying organic food products. }\end{array}$ \\
\hline Trust_2 & I trust the quality of organic food products. \\
\hline Trust_3 & $\begin{array}{l}\text { I trust the organic shop / supermarket where sells the quality } \\
\text { food product. }\end{array}$ \\
\hline Trust_4 & I trust the organic certification logo on organic food labels. \\
\hline Trust_5 & I trust store personnel who sell organic foods. \\
\hline Trust_6 & I trust the organic foods producers. \\
\hline Int_1 & I would buy organic foods in the near future. \\
\hline Int_2 & $\begin{array}{l}\text { I would recommend purchasing organic foods to a friend / } \\
\text { relative. }\end{array}$ \\
\hline Int_3 & I prefer buying organic foods to conventional ones. \\
\hline Int_4 & I am willing to pay a premium price for organic foods. \\
\hline Int_5 & I would buy organic foods for my family's health. \\
\hline Int_6 & It is the best choice for me to buy organic foods. \\
\hline Int_7 & I would buy organic foods even though choices are limited. \\
\hline
\end{tabular}

TABLE II: DEMOGRAPHIC PROFILE OF RESPONDENTS

\begin{tabular}{|c|c|c|c|}
\hline Variables & Category & $\mathrm{N}$ & Rate (\%) \\
\hline \multirow{3}{*}{ Gender } & Male & 128 & 27.5 \\
\cline { 2 - 4 } & Female & 338 & 72.5 \\
\hline \multirow{3}{*}{ Marital Status } & Single & 215 & 46.1 \\
\cline { 2 - 4 } & Married & 235 & 50.4 \\
\cline { 2 - 4 } & Separated/Divorced & 16 & 3.4 \\
\hline \multirow{4}{*}{ Ane } & $18-24$ & 97 & 20.8 \\
\cline { 2 - 4 } & $25-44$ & 349 & 74.9 \\
\cline { 2 - 4 } & $45-64$ & 18 & 3.9 \\
\cline { 2 - 4 } & $\geq 65$ & 2 & 0.4 \\
\hline \multirow{4}{*}{ Region } & $<5$ million VND & 113 & 24.2 \\
\cline { 2 - 4 } & $5-10$ million VND & 154 & 33.0 \\
\cline { 2 - 4 } & $10.1-15$ million VND & 85 & 18.2 \\
\cline { 2 - 4 } & $15.1-20$ million VND & 39 & 8.4 \\
\cline { 2 - 4 } & $>20$ million VND & 75 & 16.1 \\
\cline { 2 - 4 } & North & 136 & 29.2 \\
\cline { 2 - 4 } & Central & 36 & 7.7 \\
\hline & South & 294 & 63.1 \\
\hline
\end{tabular}

\section{RESULTS AND DISCUSSION}

Principal component analysis with varimax rotation was conducted to extract the smaller number of factors with the least losing the information that original variables provide. A KMO value of 0.906 for all statements was considered as marvelous. Thus, it was reliable to reduce dimensions of variables because the correlations of these constructs were relatively compact. Table III showed the high loadings on each factor as well as the reliability and validity of new factors through Cronbach's Alpha indicator.

H1: Attitudes towards the behavior and social norms significantly influence the organic food purchase intention.

Attitudes towards the behaviour in this study only considered about health benefits and environmental awareness. Thus, three factors - health benefits, environmental awareness, and social norms were the independent variables to evaluate the impact on the purchasing intention, which was the dependent variable in the model of multiple regression analysis.

\begin{tabular}{|c|c|c|c|}
\hline Construction & Items & Factor Loadings & Cronbach's Alpha \\
\hline \multirow{5}{*}{ Health } & Health_1 & 0.719 & \multirow{5}{*}{0.761} \\
\hline & Health_2 & 0.429 & \\
\hline & Health_3 & 0.802 & \\
\hline & Health_4 & 0.764 & \\
\hline & Health_5 & 0.476 & \\
\hline \multirow{5}{*}{ Environment } & Envi_1 & 0.581 & \multirow{5}{*}{0.841} \\
\hline & Envi_2 & 0.722 & \\
\hline & Envi_3 & 0.770 & \\
\hline & Envi_4 & 0.783 & \\
\hline & Envi_5 & 0.744 & \\
\hline \multirow{4}{*}{ Social norms } & SN_1 & 0.701 & \multirow{4}{*}{0.791} \\
\hline & SN_2 & 0.629 & \\
\hline & SN_3 & 0.678 & \\
\hline & SN_4 & 0.758 & \\
\hline \multirow{4}{*}{ Price } & Price_1 & 0.576 & \multirow{4}{*}{0.631} \\
\hline & Price_2 & 0.680 & \\
\hline & Price_3 & 0.707 & \\
\hline & Price_4 & 0.655 & \\
\hline \multirow{5}{*}{ Convenience } & Conv_1 & 0.720 & \multirow{5}{*}{0.750} \\
\hline & Conv_2 & 0.666 & \\
\hline & Conv_3 & 0.557 & \\
\hline & Conv_4 & 0.768 & \\
\hline & Conv_5 & 0.762 & \\
\hline \multirow{6}{*}{ Trust } & Trust_1 & 0.648 & \multirow{6}{*}{0.853} \\
\hline & Trust_2 & 0.613 & \\
\hline & Trust_3 & 0.776 & \\
\hline & Trust_4 & 0.819 & \\
\hline & Trust_5 & 0.729 & \\
\hline & Trust_6 & 0.776 & \\
\hline \multirow{7}{*}{ Intention } & Int_1 & 0.712 & \multirow{7}{*}{0.921} \\
\hline & Int_2 & 0.766 & \\
\hline & Int_3 & 0.775 & \\
\hline & Int_4 & 0.728 & \\
\hline & Int_5 & 0.742 & \\
\hline & Int_6 & 0.734 & \\
\hline & Int 7 & 0.775 & \\
\hline
\end{tabular}

$\mathrm{R}^{2}$ ( $\mathrm{R}$ Square) is a measure of the proportion of the total variability in the outcome accounted for by the predictors [23] Three predictors (Health, Environment and Social norms) together can explain 42.5 percent of the variance in the purchasing intention of organic foods (see Fig. 2)

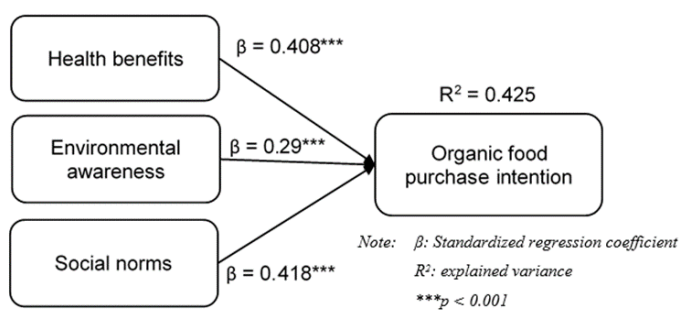

Fig. 2. Results of multiple regression model for organic food purchase intention.

Predictors (health, environment and social norms variables) had the positive $\beta$ value indicating positive relationships with purchase intention, and all these variables made a significant contribution to the model $(\mathrm{p}<0.001)$. Furthermore, health $(\beta$ $=0.408, \mathrm{p}<0.001)$ and social norm $(\beta=0.418, \mathrm{p}<0.001)$ had the stronger impact on the intention than environment $(\beta=$ $0.29, \mathrm{p}<0.001$ ) factor based on $\beta$ value.

This empirical study confirms that health awareness is considered as the key determinant affecting the organic food 
purchase intention regardless of different nations with diverse cultures [11], [13], [22]. Undoubtedly, health is convincingly the most important concern in food choices of the global consumers in general [24] and Vietnamese buyers in particular [25].

Social media and opinions of other people strongly influence the individual's organic food purchase intention. Moreover, flaunting the social status or desirability of impressing others may also lead to high intention of choosing organic foods [26]. Vietnamese participants in this study reported the similar results. Obviously, individuals are more likely to take surrounding people's opinions into account [27] and to act based on the others' support [28]. This can explain for the reason why the roles of social media and peers' recommendation considerably influence the purchase intention in Vietnam. This situation can be different from that in developed countries where social needs have been met, thereby negligible influence of subjective norms [11]. However, this respect cannot be generalized for all developed countries as diverse traditions and cultures can also make the difference. Ruiz de Maya et al. pointed out the consistent results that subjective norms exerted the consumers' intention to buy organic food in several countries in Europe such as Italy, Denmark, the UK, Finland, Greece, Germany, and Sweden [29]. Further, the findings from some Asian countries (e.g. Cambodia, Sri Lanka, and India) indicate that the intention of organic food consumption comes from the individuals' motivation rather than influential people or social media [21], [26].

Vietnamese respondents held the positive perception of organic foods with respect to environmental benefits. The intention motive concurs with previous studies in Vietnam [8], and across many countries worldwide such as Poland [13], China [30], Thailand and Cambodia [26], Turkey [12] and other developed countries [11]. Conversely, no significant relationship between environmental concerns and the purchase intention of organic foods was found among Indian consumers [21].

Furthermore, the outcome of the present study also noticed that health benefits and social norms were more influenced on the intention than environmental awareness. Food safety in developing countries including Vietnam is still the alarming issue these days [11], [31]. Noticeably, the outbreaks of unsafe food in Vietnam have regularly happened across the food supply chain, from the overuse of pesticides at the farm level [6] to the poor safety practices of distributors [32]. What is more, the risk communication of authorities is quite poor regarding food safety [31]. Hence, the fact that Vietnamese consumers pay high attention to the health factor is not surprising.

H2: Trust, convenience and availability, and price negatively influence organic food purchase behavior.

Many studies indicated that high purchasing intention of consumers did not translate into the actual purchasing behaviour [10], [33]. Thus, opportunity and ability in the MOA model are considered as two determinants explaining a disparity between intention and behaviour. If these determinants can be thoroughly understood, they would be the good indicators for the government and other stakeholders to consider about narrowing the intention - action gap.
Linear multiple regression analysis was applied to test the relationship between Purchase Behaviour (dependent variable) and Intention, Price, Trust, Convenience and availability (independent variables). The results are described in Fig. 3.

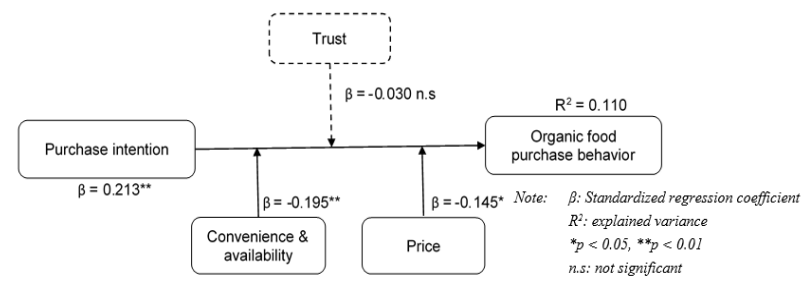

Fig. 3. Results of multiple regression model for organic food purchase behavior.

All four predictors (Intention, Trust, Convenience, and Price) together can explain only 11.0 percent of the variance in actual purchasing behavior in organic foods.

Intention has the positive $\beta$ value indicating positive relationships with purchase behavior, while price, convenience, and trust have the negative relationship with purchase behavior demonstrated through negative $\beta$ value. Moreover, intention $(\beta=0.213, \mathrm{p}=0.001)$, convenience $(\beta=$ $-0.195, \mathrm{p}=0.001)$, and price $(\beta=-0.145, \mathrm{p}=0.020)$, which have the $\mathrm{p}$-value less than 0.05 , make a significant contribution to the model. Trust factor $(\beta=-0.030, \mathrm{p}=0.626)$, which has $\mathrm{p}$-value $>0.05$, does not significantly contribute to this model.

Intention positively influences purchase behavior towards organic foods. Price and convenience are the deterrent factors preventing Vietnamese consumers from buying organic foods although they have high purchase intention. Lack of trust does not significantly influence purchase behavior towards organic foods. It was repeatedly claimed that intention had a strong predictor of organic food purchase behavior [21], [34]. Thus, enhancing and strengthening the intention may increase the actual organic food consumption.

In line with some research findings [13], [15], [21], the result of this study ascertained that high price and inconvenience or unavailability were the deterrent factors of organic food purchase behavior although the strong intention was prevailed. High price constrained conventional consumers to fully shift to organic food consumption [9]. Moreover, some consumers link the premium price of organic foods with the high quality and high status, thereby the sign of high price contributing to the positive meaning of organic products [35].

To meet the growing demand for organic products, conventional supermarkets unhesitatingly added such items to their shelves to make more available to customers [14]. However, inconvenience to buy or unavailability of organic categories is still existed in the market and demotivates consumers to buy organic products. Therefore, organic consumers are reluctant to buy organic products [31]. This context is similar to the situation in other countries such as Indonesia [16], India [21], and Poland [13] where the availability of organic products has been confined. Direct sale from farmers to consumers is an option to have the affordable price for organic products. Community Support Agriculture 
(CSA), one of the possibilities for directly connecting consumers with farmers [36], should be concerned to practice in Vietnam. CSA is a partnership of mutual commitments between growers (producers) and members or shareholders (consumers). Members provide financial support for farmers to grow seasonal fresh produce through agreed monthly membership fees. In return, consumers receive a weekly box with different varieties of organic vegetables. Consumers and producers are sharing the risks and benefits of food production [37]. This agricultural practice has been popularly implemented in Europe and North America [38]. Any articles and information with respect to CSA in Vietnam has not been found yet.

\section{CONCLUSION AND IMPLICATIONS}

This study supports that health benefits, environmental awareness, and social norms are facilitators of organic food purchase intention. Thus, local authorities and marketing practitioners should emphasize the benefits of organic food production and consumption regarding health and environmental aspects through effective communication programs such as advertisements, campaigns, or story-telling strategies. Stories of organic farming, talk shows with doctors or nutritionists about organically produced foods and other topics regarding sustainable consumption should be broadcasted on Vietnamese television during the primetime slots $-7: 30$ am and 8:30 pm to gain high attention from consumers. This suggestion can provide better insight into organic food and agriculture for Vietnamese consumers, thereby high possibility of enhancing the intention of organic food consumption through social media and word-of-mouth. Further, intention was confirmed as the strong predictor for the purchase behavior in this research.

The application of MOA model allows explaining the intention - behavior gap with respect to organic food consumption. Although high intention to purchase organic foods was found among Vietnamese consumers, premium price and low availability of organic products or inconvenience to buy are deterrent factors of the engagement in actual purchase behavior. From these findings, short food supply chains, and other pricing strategies as well as efforts to improve the efficient distribution channels should be made in order for consumers to approach the authentic organic produce. CSA is one of potential solutions to directly connect consumers to farmers. Consumers through this agricultural practice can share the risks and benefits with growers. Moreover, shareholders are able to know the origin of the products they consume daily. Additionally, food industry should promote the advantages of organic foods to convince consumers that premium prices of organic products are justified. Temporarily discounted price for organic products should be also considered as the promotion strategy to tempt non-organic consumers to experience these commodities. Furthermore, organic consumers simultaneously take the price reduction for granting, thereby stimulating organic purchase. This pricing strategy is definitely not a long-term solution for green products.

\section{LIMITATIONS AND FUTURE RESEARCH}

This research is a starting point to identify some facilitators of intention to purchase organic food as well as several determinants of discrepancies between intentions and actual behaviors. Further investigations should include more factors such as sensory appeal, labelling, ethical consumer identity, previous experience, locally organic produce, and etc. to have better understanding of the motives encouraging and barriers hindering consumers from organic food choices. The data collection for organic food purchase behavior was based on self-administrative report which may provide distorted information due to social desirability. Thus, panel data collection with scanning technology may improve the data reliability regarding actual purchase behavior. Moreover, the differentiation between the act of purchasing and the actual consumption regarding organic foods has been paid little attention by scientists [34]. Thus, future research should investigate and distinguish purchase behavior and consumption behavior. Consequently, winning marketing strategies can be made.

\section{ACKNOWLEDGMENT}

Financial support and online survey platform were sponsored by University of Kassel, Germany.

\section{REFERENCES}

[1] L. Seconda, J. Baudry, B. Allès, O. Hamza, C. Boizot-Szantai, L. G. Soler et al., "Assessment of the sustainability of the Mediterranean diet combined with organic food consumption: An individual behaviour approach," Nutrients, vol. 9, no. 1, pp. 1-15, January 2017.

[2] FAO-WHO (1999). CAC/GL 32-1999. Guidelines for the production, processing, labelling and marketing of organically produced foods. Food and Agriculture Organization of the United Nations (FAO), World Health Organization (WHO). [Online]. Available: http://www.fao.org/fao-who-codexalimentarius/standards/list-of-stand ards/en/

[3] World Bank. (2017). How are the income group thresholds determined? World Bank. [Online]. Available: https://datahelpdesk.worldbank.org/knowledgebase/articles/378833-h ow-are-the-income-group-thresholds-determined

[4] T. H. Nguyen and T. K. O. Nguyen, "Chemical characterization and sources apportionment of fine particulate pollution in a mining town of Vietnam," Atmospheric Research, vol. 145, pp. 214-225, August 2014.

[5] Q. H. Vuong and K. N. Nancy, "Resource curse or destructive creation in transition," Management Research Review, vol. 37, no. 7, pp. 642-657, 2014.

[6] World Bank. (2016). Vietnam development report 2016. Transforming Vietnamese agriculture. Gaining more from less. World Bank. [Online]. Available:

http://documents.worldbank.org/curated/en/116761474894023632/pd f/108510-WP-PUBLIC.pdf

[7] VecoVietnam. Safe and organic vegetables in Vietnam. Rikolto in Vietnam. [Online]. Available: https://vietnam.veco-ngo.org/en/project/safe-and-organic-vegetablesvietnam\#tab-story

[8] H. D. M. Nguyen, P. Rutsaert, E. J. van Loo, and W. Verbeke, "Consumers' familiarity with and attitudes towards food quality certifications for rice and vegetables in Vietnam," Food Control, vol. 82, pp. 74-82, December 2017.

[9] S. Hemmerling, U. Hamm, and A. Spiller, "Consumption behaviour regarding organic food from a marketing perspective: A literature review," Organic Agriculture, vol. 5, no. 4, pp. 277-313, December 2015.

[10] G. Torma, J. Aschemann-Witzel, and J. Thøgersen, "I nudge myself. Exploring 'self-nudging' strategies to drive sustainable consumption behaviour," International Journal of Consumer Studies, vol. 42, no. 1, pp. 141-154. January 2018. 
[11] J. Rana and J. Paul, "Consumer behavior and purchase intention for organic food: A review and research agenda," Journal of Retailing and Consumer Services, vol. 38, pp. 157-165, September 2017.

[12] S. Çabuk, C. Tanrikulu, and L. Gelibolu, "Understanding organic food consumption: Attitude as a mediator," International Journal of Consumer Studies, vol. 38, no. 4, pp. 337-345, July 2014.

[13] P. Bryła, "Organic food consumption in Poland: Motives and Barriers," Appetite, vol. 105, pp. 737-746, October 2016.

[14] T. B. Hossain and P. X. Lim, "Consumers' buying behavior towards organic foods: Evidence from the emerging market," Malaysian Institute of Management, vol. 51, no. 2, pp. 7-25, July-December 2016.

[15] A. K. Moser, "Buying organic-decision-making heuristics and empirical evidence from Germany," Journal of Consumer Marketing, vol. 33, no. 7, pp. 552-561, 2016.

[16] B. Suharjo, M. Ahmady, and M. R. Ahmady, "Indonesian consumers' attitudes towards organic products," Advances in Economics and Business, vol. 4, no. 3, pp. 132-140, 2016.

[17] F. Olander and J. Thøgersen, "Understanding of consumers behaviour as a prerequisite for environmental protection," Journal of Consumer Policy, vol. 18, no. 4, pp. 345-385, December 1995.

[18] I. Ajzen, "Consumer attitudes and behavior: The theory of planned behavior applied to food consumption decisions," Rivista di Economia Agraria, vol. 70, no. 2, pp. 121-138, January 2015.

[19] C. C. Teng and Y. M. Wang, "Decisional factors driving organic food consumption: Generation of consumer purchase intentions," British Food Journal, vol. 117, no. 3, pp. 1066-1081, 2015.

[20] T. T. Truong, M. H. T. Yap, and E. M. Ineson, "Potential Vietnamese consumers' perceptions of organic foods," British Food Journal, vol. 114, no. 4, pp. 529-543, 2012.

[21] R. Yadav and G. S. Pathak, "Intention to purchase organic food among young consumers: Evidences from a developing nation," Appetite, vol. 96, pp. 122-128, January 2016.

[22] H. J. Lee, "Individual and situational determinants of U.S. consumers' buying behavior of organic foods," Journal of International Food \& Agribusiness Marketing, vol. 28, no. 2, pp. 117-131, January 2016.

[23] A. P. Field, Discovering Statistics Using IBM SPSS Statistics. And Sex and Drugs and Rock ' $n$ ' Roll, 4th ed. London: SAGE, 2013, p. 336.

[24] C. Oroian, C. Safirescu, R. Harun, G. Chiciudean, F. Arion, I. Muresan, and B. Bordeanu, "Consumers' attitudes towards organic products and sustainable development: A case study of Romania," Sustainability, vol. 9, no. 9, pp. 1559-1574, September 2017.

[25] M. H. Ngo, M. Moritaka, and S. Fukuda, "Willingness to pay for organic vegetables in Vietnam: An empirical analysis in Hanoi Capital," Journal of the Falculty of Agriculture, Kyushu University, vol. 58, no. 2, pp. 449-458, September 2013.

[26] P. Pomsanam, K. Napompech, and S. Suwanmaneepong, "An exploratory study on the organic food purchase intention among Thai-Cambodian cross-border consumers," Asian Journal of Applied Sciences, vol. 7, no. 5, pp. 294-305, 2014.

[27] P. D. Nghia, "Confucianism and the conception of the law in Vietnam," in J. Gillespie, P. Nicholson, Eds. Asian Socialism \& Legal Change. The Dynamics of Vietnamese and Chinese Reform, 1st Canberra, Australia: The Australian National University E Press and Asia Pacific Press, 2005, pp. 76-90.

[28] N. T. Thong, D. H. Nguyen, P. T. N. Bich, and L. T. M. Huong, "Sustainable consumption and production in Vietnam," in P. Schroeder, K. Anggraeni, S. Sartori, and U. Weber, Eds. Sustainable Asia, World Scientific, 2017, pp. 327-356.

[29] S. R. Maya, I. López-López, J. L. Munuera, "Organic food consumption in Europe: International segmentation based on value system differences," Ecological Economics, vol. 70, no. 10, pp. 1767-1775, August 2011.

[30] J. Chen, A. Lobo, and N. Rajendran, "Drivers of organic food purchase intentions in mainland China: Evaluating potential customers' attitudes, demographics and segmentation," International Journal of Consumer Studies, vol. 38, no. 4, pp. 346-356, July 2014.

[31] H. Nguyen-Viet, T. T. Tuyet-Hanh, F. Unger, S. Dang-Xuan, and D. Grace, "Food safety in Vietnam: Where we are at and what we can learn from international experiences," Infectious Diseases of Poverty, vol. 6, no. 1, February 2017.

[32] P. H. Luu, B. Davies, and M. P. Dunne, "The association between factors which affect the food safety practices of seafood distributors within the southern domestic distribution chains in Vietnam," Food Control, vol. 73, pp. 332-340, March 2017.
[33] I. Schäufele and U. Hamm, "Organic wine purchase behaviour in Germany: Exploring the Attitude-behaviour-gap with data from a household panel," Food Quality and Preference, vol. 63, pp. 1-11, 2018.

[34] A. Scalco, S. Noventa, R. Sartori, and A. Ceschi, "Predicting organic food consumption: A meta-analytic structural equation model based on the theory of planned behavior," Appetite, vol. 112, pp. 235-248, May 2017.

[35] H. Hasimu, S. Marchesini, and M. Canavari, "A concept mapping study on organic food consumers in Shanghai, China," Appetite, vol. 108, pp. 191-202, January 2017

[36] G. Smith, D. Nandwani, and V. Kankarla, "Facilitating resilient rural-to-urban sustainable agriculture and rural communities," International Journal of Sustainable Development \& World Ecology, vol. 24 , no. 6, pp. 485-501, October 2016

[37] USDA (2017). The alternative farming systems information center Community supported agriculture. United States department of agriculture. [Online]. Available: https://www.nal.usda.gov/afsic/community-supported-agriculture

[38] P. Kop, K. Nijhof, H. Kloen, and A. Braun, "Community supported agriculture: An alternative local food system," Leisa Magazine, vol. 24, no. 1, pp. 32-34, March 2008.

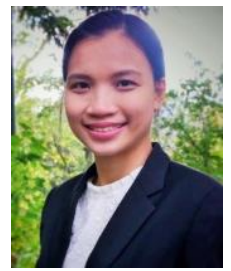

Loan H. Tran obtained her master degree in international food business \& consumer studies at the University of Kassel and Fulda University of Applied Sciences. She took part in the organizing teams of Healthy Ageing Conference and Lecture Series inspired by Model United Nations. The former was organized in Fulda, Germany in March 2017, while the latter was held in Witzenhausen, Germany from October 2017 to January 2018 with the themes of Climate Change, Migration and Violent Extremism: The United Nations' Role in Preventing Conflicts Spurred by the Challenges of Our Time. Her research interests are sustainable consumption behavior and sustainable business.

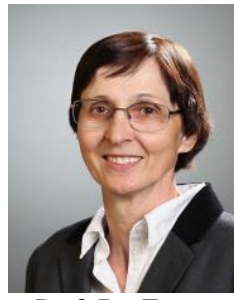

Barbara Freytag-Leyer is a senior researcher at Fulda University of Applied Sciences, Fulda, Germany. She acquired her Ph.D at Justus-Liebig University Giesen, Germany in 1996 and was professor of socio-ecology of the private households from 1999 to 2016. Her research interests include household / household services, living and caring for private households in rural and urban areas, society and sustainability.

Prof. Dr. Freytag-Leyer is currently a member of Deutschen Gesellschaft für Hauswirtschaft e.V. (dgh), International Federation for Home Economics (IFHE) und IFHE Household Technology and Sustainability Committee.

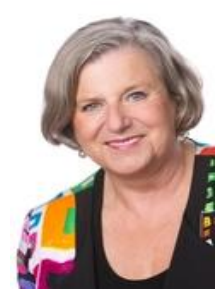

Angelika Ploeger is the senior researcher in the Department of Organic Food Quality and Food Culture, Faculty of Organic Agricultural Sciences, University of Kassel, Witzenhausen Campus, Germany. She was awarded a doctorate in 1978, and has become the professor since 1984 . Her research is focusing on organic food quality and food culture as well as nutrition ecology and product development.

Prof. Ploeger joins the memberships of many international organizations including International Society of Organic Agricultural Research (ISOFAR), Deutsche Landwirtschafts-Gesellschaft e.V. (DLG), Wissenschaftlicher Beirat Bund Ökologische Lebensmittelwirtschaft (BÖLW), to mention but a few.

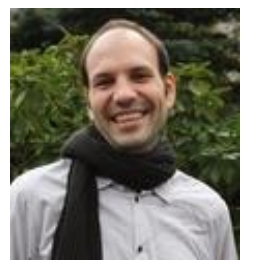

Thomas Krikser is a lecturer and researcher in Department of Agricultural and Food Marketing, Faculty of Organic Agricultural Sciences, University of Kassel, Witzenhausen Campus, Germany. His research focuses are on empirical social research, education for sustainable development, payments for ecosystem services, urban agriculture and civil society. 